\title{
Alüviyal Ortamda Derin Kazı Problemi
}

\author{
${ }^{1}$ Aşkın Özocak, ${ }^{1}$ Sedat Sert, ${ }^{* 1}$ Ertan Bol \\ ${ }^{*}$ Sakarya Üniversitesi, Mühendislik Fakültesi, İnşaat Mühendisliği Bölümü, 54187, Sakarya, Türkiye
}

\section{Özet}

Kent merkezlerinde ortaya çıkan bodrum ihtiyaçları Geoteknik Mühendisliği'nin önemli konularından biri olan derin kazı problemleri ile daha sık karşılaşma durumunu ortaya çıkarmıştır. Bu durum hem kısa vadede hem de uzun vadede farklı kayma direnci parametrelerinin uyanabildiği özellikle derin kazı yapılması gibi çalışmalarda zemin ve kaya ortamlar için ilave bir özen ve tecrübe gereksinimi doğurmaktadır. Bu bildiride, Adapazarı kent merkezinde inşası planlanan ve gerçekleştirilen bir derin kazı çalışması kapsamında zemin inceleme, analiz, imalat ve deformasyon durumu aşamaları değerlendirilmiştir. Kazıklı perdenin imalatını takiben gerçekleştirilen $4 \mathrm{~m}$ derinliğindeki kazı ve doldurma aşaması sonrası özellikle doğu cephesindeki deformasyon okumaları dikkat çekmiş ve SAÜ Geoteknik Çalışma Grubu tarafindan olayın nedenlerinin anlaşılması ve varsa gerekli tedbirlerin alınmasına yönelik olarak bir bilimsel çalışma yapılmıştır. Yapılan inceleme sonunda bu durumun özellikle kazıkların imali sırasında yeraltı suyunda ani drenajın gerçekleşmesi ve bunun sonrasında bitişik nizamda bulunan mevcut 5 katlı yapının altında yer alan özellikle killi tabakaların konsolide olmasından kaynaklandığı tahmin edilmiştir. Kazı projelendirilen yatay destek sistemiyle başarıyla sonlandırılmış olup derin kazı destek sisteminde destek (strut) uygulamasının pratikte kazı aşamasında özellikle küçük parsellerde uygulama zorluğu yarattığı gözlemlenmiştir.

Anahtar Kelimeler: Zemin mekaniği, derin kazı destek sistemi, deformasyon okumaları

\section{Deep Excavation Problem in Alluvial Soil}

\author{
${ }^{1}$ Aşkın Özocak, ${ }^{1}$ Sedat Sert, ${ }^{* 1}$ Ertan Bol \\ ${ }^{* 1}$ Sakarya University, Engineering Faculty, Civil engineering Department, 54187, Sakarya, Türkiye
}

\begin{abstract}
The basement needs that emerged in the city centers have led to a more frequent encounter with deep excavation problems, which is one of the important issues of Geotechnical Engineering. This situation requires additional care and experience for soil and rock environments especially in deep excavations where different shear resistance parameters can be mobilized both in the short term and in the long term. In this paper, the stages of soil investigation, analysis, manufacturing and measured deformation were evaluated within the scope of the deep excavation planned and carried out in Adapazari city center. Following the excavation and filling phase at a depth of $4 \mathrm{~m}$ following the construction of the secant piles, the deformation readings were particularly noticeable on the eastern border. SAU Geotechnical Working Group conducted an investigation study to understand the causes of the incident and to take the necessary measures, if any. After the investigation, the reason of the deformations was estimated to be due to the sudden drainage of groundwater during the construction of the piles, and subsequent consolidation of the clayey layers beneath the existing 5-storey structure adjacent to it. The excavation has been successfully completed with the projected horizontal support system and it has been observed that the application of strut in the deep excavation support system creates practical difficulties especially in small parcels during the excavation phase.
\end{abstract}

Key words: Soil mechanics, deep excavation retaining system, deformation readings

*Corresponding author: Address: Faculty of Engineering, Department of Civil Engineering Sakarya University, 54187, Sakarya TURKEY. E-mail address: ebol@ sakarya.edu.tr, Phone: +902642955746 


\section{Giriş}

Yeni yaşam alanlarında yer alan arsa maliyetlerinin artması yüksek yapılaşma talebinin yanı sıra bodrum kat ihtiyaçlarının da artması durumunu ortaya çıkartmaktadır. Günümüzde ülkemizde gerçekleştirilen on metreyi aşan derinliklerdeki temel kazısı örnekleri giderek artmaktadır. Bununla birlikte uzman geoteknik mühendislerince yapılmayan hesap ve kontrol edilmeyen uygulamalarda meydana gelen kazalar neticesinde can ve mal kayıplarıyla karşılaşılan örnekler de göze çarpmaktadır. Güvenilir bir çalışma için öncelikle zemin özelliklerinin gerçeğe en yakın bir şekilde belirlenmesi, hesaplamaların ve analizlerin ortam koşullarını doğru yansıtır şekilde yapılması gerekmektedir. Ayrıca analiz sonuçlarının doğru bir şekilde değerlendirilmesi ve hem güvenilir hem de ekonomik şekilde boyutlandırma yapılabilmesi için yeterli bilgi ve tecrübe gereksinimi doğmaktadır.

Bu çalışmada Sakarya İli'nde inşası planlanan yapı öncesi gerekli derin kazı çalışması için gerçekleştirilen saha çalışması, laboratuvar çalışması ve buradan elde edilen verilerin kullanımı ile yapılan analiz ve değerlendirmeler sonucu ortaya çıkan boyutlandırma uygulamasından bahsedilmektedir. Yapılan çalışmalar uygulama safhasında deformasyon okumalarının alınması ve imalatın takibi aşamalarını da içermektedir.

İnşası planlanan yapı bodrum katı $500 \mathrm{~m}^{2}$ oturma alanına sahip 2 bodrum + zemin +2 normal katlı olarak tasarlanmıştır. Ortalama $18 \mathrm{~m}$ x $28 \mathrm{~m}$ boyutlara sahip binanın temel sistemi yayılı (radye) temel ve maksimum temel gömme derinliği $\left(\mathrm{D}_{\mathrm{f}}\right)$ de 9.00 metre olarak planlanmıştır. Yapının oturacağı alan birinci derece deprem bölgesinde kalmakta olup bölge 10 ile 30 y1l aralıklarla büyük depremlere maruz kalmaktadır [1].

Çalışma alanı Akova üzerinde yer alan Adapazarı kent merkezinde yer almaktadır (Şekil 1). Şehir merkezinin üzerinde yer aldığı, Sakarya Nehri'nin taşıdığı malzeme ile oluşmuş olan alüvyon birikintinin kalınlığı yaklaşık $1 \mathrm{~km}$ olarak tahmin edilmektedir [2]. Bölgede yeraltı su seviyesinin zemin yüzeyine yakın olması temel kazısı problemini ayrıca kritik hale getirmektedir.

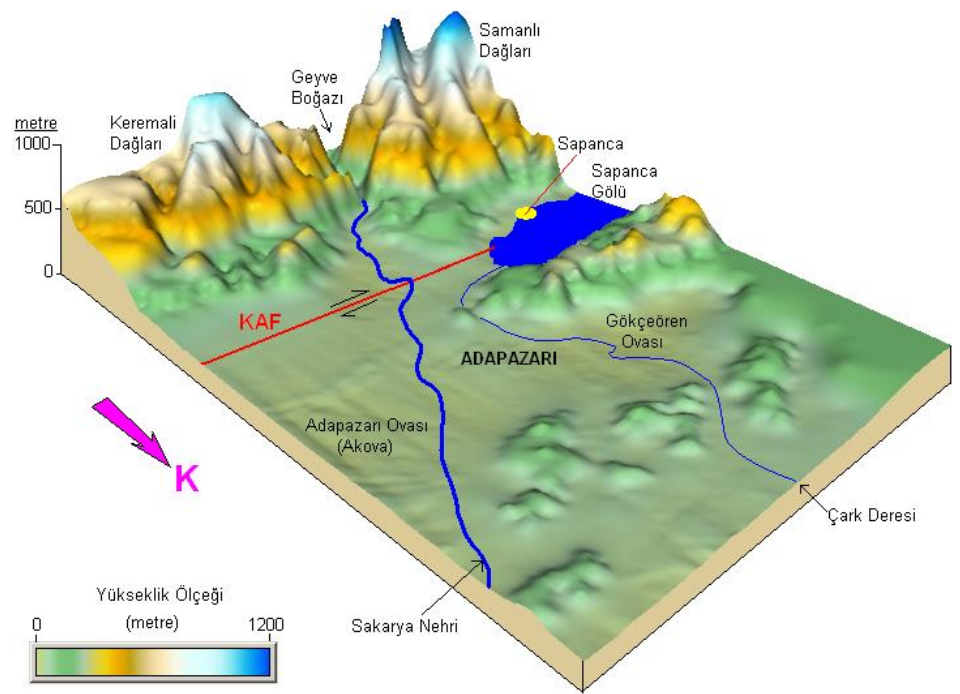

Şekil 1. Adapazarı'nın KD'dan GB'ya doğru morfolojik görünümü [3] 


\section{Malzeme ve Yöntem}

Çalışma alanında inşası planlanan yapı için; zemin özelliklerinin belirlenmesi, temel boyutlandırılması ve derin kazı analizine yönelik olarak daha önce yaptırılmış olanlara ilaveten 2 adet 25 'er $\mathrm{m}$ derinliğinde muhafazalı dönel sondaj yaptırılmıştır. Sondaj yerlerini de içeren vaziyet planı Şekil 2'de verilmiştir. Çalışma alanının doğu cephesinde bitişik nizamda, temel kazısı aşamasında kritik duruma geçecek olan 5 katlı mevcut bir yapı bulunmaktadır. Sondaj logları incelendiğinde parsel zemininin üst 4 metresinde kazı yapılarak doldurulmuş olduğu beyan edilen killi, kumlu dolgu malzemesinin bulunduğu, bu derinlikten sonra ise 7.50 m'ye kadar orta plastisiteli killerin var olduğu ve sonrasında ise siltli kum tabakalarının yer aldığ anlaşılmaktadır. 16 metre derinlikten sonra ise tekrar killi birimlere girildiği görülmektedir. Çalışma alanında yer altı su seviyesi -3.00 m olarak rapor edilmişstir.

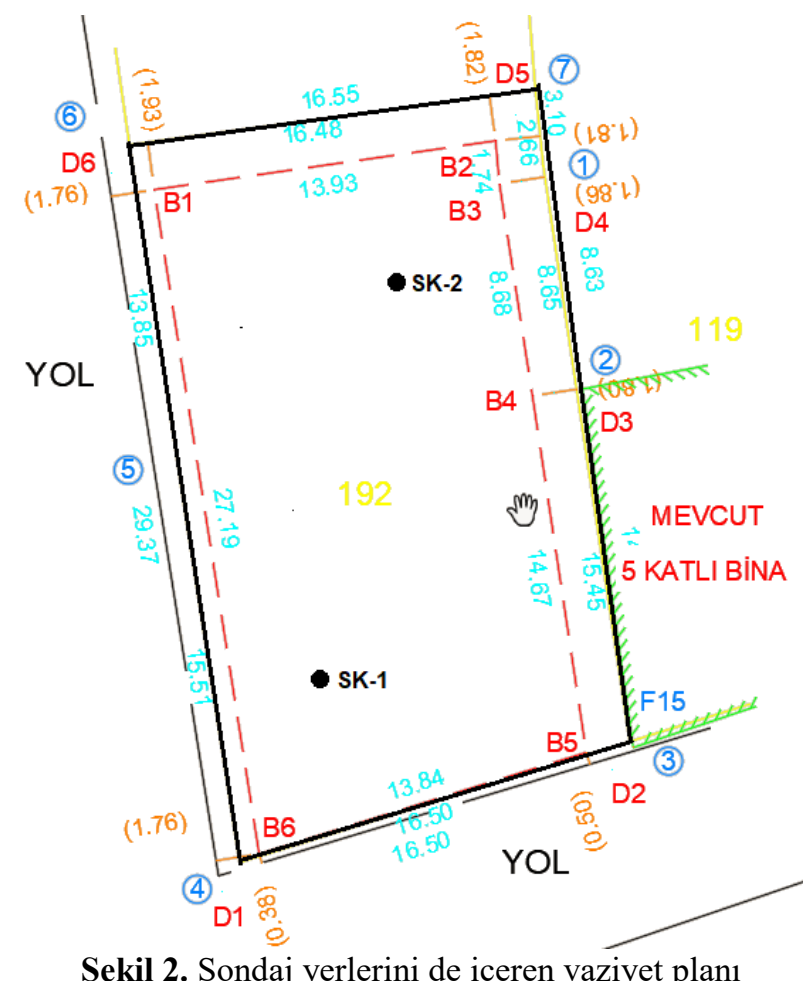

Şekil 2. Sondaj yerlerini de içeren vaziyet planı

\subsection{Laboratuvar çalışmaları}

Zemin incelemeleri sırasında ölçülen fiziksel özellikler araştırmacıya sanılandan çok daha fazla bilgi sağlar. Çalışma alanında daha önce inşa edilmiş olan bir bodrumlu yapının yıkımından dolayı parselin yaklaşık \%60'lık kısmında yıkım sonrası kontrolsüzce doldurulan killi malzeme bulunmaktadır. Araziden alınan numuneler Sakarya Üniversitesi Geoteknik Laboratuvarında deneysel incelemeye tabi tutulmuşlardır. TS 1900/1 ve 2 (2006) [4, 5] uyarınca gerçekleştirilen deney sonuçları aşağıda sıralanmıştır. Tablo 1'de ise zeminlerin fiziksel özellikleri özet halde verilmektedir. 
Tablo 1. Çalışma Alanı Zemin Özellikleri

\begin{tabular}{cccccccclccc}
\hline SK & Derinlik & Renk & Wn & wL & WP & PI & IL & Sınıf & \% G & \% & SC \\
\hline $\mathbf{1}$ & $1.50-1.95$ & YK & 40 & 68 & 23 & 45 & 0.38 & CH & & 2 & 98 \\
$\mathbf{1}$ & $2.00-2.50$ & KG & 24 & NP & NP & NP & & SM & & 58 & 42 \\
$\mathbf{1}$ & $4.50-4.95$ & Y & 29 & 41 & 23 & 18 & 0.38 & CI & & 36 & 64 \\
$\mathbf{1}$ & $5.00-5.50$ & Y & 40 & 49 & 22 & 27 & 0.67 & CI & & 11 & 89 \\
$\mathbf{1}$ & $7.50-7.95$ & kGY & 16 & NP & NP & NP & & SM & 19 & 69 & 12 \\
$\mathbf{1}$ & $10.50-10.95$ & GY & 26 & NP & NP & NP & & SP-SM & & 92 & 8 \\
$\mathbf{1}$ & $13.50-13.95$ & G & 27 & NP & NP & NP & & SP-SM & 3 & 89 & 8 \\
$\mathbf{1}$ & $16.50-16.95$ & Y & 36 & 45 & 25 & 20 & 0.58 & CI & & & 100 \\
$\mathbf{1}$ & $19.50-19.95$ & Y & 36 & 65 & 24 & 41 & 0.28 & CH & & & 100 \\
$\mathbf{2}$ & $3.00-3.45$ & Y & 34 & 34 & 26 & 8 & 0.85 & ML & & 38 & 62 \\
$\mathbf{2}$ & $3.50-4.00$ & KY & 36 & 38 & 19 & 19 & 0.85 & CI & & 19 & 81 \\
$\mathbf{2}$ & $6.00-6.45$ & YG & 37 & 44 & 29 & 15 & 0.54 & MI & & 2 & 98 \\
$\mathbf{2}$ & $9.00-9.45$ & Y & 21 & NP & NP & NP & & SM & & 83 & 17 \\
$\mathbf{2}$ & $12.00-12.45$ & YG & 23 & NP & NP & NP & & SP-SM & 14 & 76 & 10 \\
$\mathbf{2}$ & $15.00-15.45$ & Y & 36 & 73 & 23 & 50 & 0.26 & CH & & 1 & 99 \\
$\mathbf{2}$ & $18.00-18.45$ & Y & 36 & 68 & 25 & 43 & 0.25 & CH & & 1 & 99 \\
\hline \multicolumn{7}{c}{ K: Kahve Y: Yeşil } & G: Gri & B: Krem & a: aç1k k: koyu & &
\end{tabular}

Tablo 2-6' da parsel zeminlerinin mekanik deney sonuçları özetlenmiş olup temel çukurunda dengenin sağlanması amacıyla yapılan derin kazı analizlerinde bu veriler göz önüne alınmıştır. $\mathrm{Bu}$ tablolarda görüleceği üzere zeminlerin mekanik özelliklerinin belirlenmesi aşamasında numuneler üzerinde üç eksenli hücre kesme deneyleri (UU ve CU), tek eksenli serbest basma deneyi, kesme kutusu deneyleri ve konsolidasyon deneyi gerçekleştirilmiştir. Bu sayede alan zeminlerinin hem efektif hem de toplam gerilme kayma direnci parametreleri ve sıkışma özellikleri belirlenmiştir.

Tablo 2. Çalışma Alanı UU Deney Sonuçları

\begin{tabular}{llllllllll}
\hline SK & $\mathbf{z}(\mathbf{m})$ & Renk & Sinıf & $\mathbf{w n}_{\mathbf{n}}(\boldsymbol{\%})$ & $\mathbf{e}$ & $\boldsymbol{\rho}\left(\mathbf{k N} / \mathbf{m}^{\mathbf{3}}\right)$ & $\mathbf{S}_{\mathbf{r}}(\boldsymbol{\%})$ & $\mathbf{c}_{\mathbf{u}}(\mathbf{k P a})$ & $\mathbf{P}(\mathbf{k P a})$ \\
\hline 2 & $3.50-4.00$ & KY & CI & 36.5 & 0.88 & 19.00 & 100 & 23 & 100 \\
\hline
\end{tabular}

Tablo 3. Çalışma Alanı UC Deney Sonuçları

\begin{tabular}{llllllllll}
\hline SK & $\mathbf{z}(\mathbf{m})$ & Renk & Sinıf & $w_{\mathbf{n}}(\boldsymbol{\%})$ & e & $\boldsymbol{\rho}\left(\mathbf{k N} / \mathbf{m}^{\mathbf{3}}\right)$ & $\mathbf{S}_{\mathbf{r}}(\boldsymbol{\%})$ & $\mathbf{c}_{\mathbf{u}}(\mathbf{k P a})$ & $\mathbf{P}(\mathbf{k P a})$ \\
\hline 1 & $2.00-2.50$ & YK & SM & 40 & 1.04 & 17.98 & 100 & 49 & - \\
\hline
\end{tabular}

Tablo 4. Çalışma Alanı Kesme Kutusu Deney Sonuçları

\begin{tabular}{llllllllll}
\hline SK & $\mathbf{z}(\mathbf{m})$ & Renk & Sinıf & $\mathbf{W n}_{\mathbf{n}}(\boldsymbol{\%})$ & $\mathbf{e}$ & $\boldsymbol{\rho}\left(\mathbf{k N} / \mathbf{m}^{\mathbf{3}}\right)$ & $\mathbf{S}_{\mathbf{r}}(\boldsymbol{\%})$ & $\mathbf{c}(\mathbf{k P a})$ & $\boldsymbol{\phi}\left(^{\circ}\right)$ \\
\hline 2 & $5.50-6.00$ & GY & 1 & 29 & 0.86 & 18.18 & 91 & 0 & 34 \\
\hline
\end{tabular}

Tablo 5. Çalışma Alanı CU Deney Sonuçları

\begin{tabular}{lllllllllll}
\hline SK & $\mathbf{z}(\mathbf{m})$ & Renk & Sinıf & $\mathbf{w}_{\mathbf{n}}(\boldsymbol{\%})$ & $\mathbf{e}$ & $\boldsymbol{\rho}\left(\mathbf{k N} / \mathbf{m}^{\mathbf{3}}\right)$ & $\mathbf{S}_{\mathbf{r}}(\boldsymbol{\%})$ & $\mathbf{c}^{\mathbf{I}}(\mathbf{k P a})$ & $\boldsymbol{\phi}^{\mathbf{1}}\left(^{\circ}\right)$ & $\mathbf{P}(\mathbf{k P a})$ \\
\hline 1 & $5.00-5.50$ & $\mathrm{Y}$ & CI & 39 & 1.00 & 18.4 & 100 & 14 & 33 & 160 \\
\hline
\end{tabular}


Tablo 6. Çalışma Alanı Konsolidasyon Deney Sonuçları

\begin{tabular}{lllllllllllll}
\hline $\mathbf{S K}$ & $\mathbf{z}(\mathbf{m})$ & Renk & Sinıf & $\mathbf{w n}_{\mathbf{n}}(\boldsymbol{\%})$ & $\mathbf{e}$ & $\boldsymbol{\rho}\left(\mathbf{k N} / \mathbf{m}^{\mathbf{3}}\right)$ & $\mathbf{S}_{\mathbf{r}}(\boldsymbol{\%})$ & $\mathbf{C}_{\mathbf{c}}$ & $\mathbf{C}_{\mathbf{r}}$ & $\boldsymbol{\sigma}_{\boldsymbol{\theta}}{ }^{\mathbf{1}}(\mathbf{k P a})$ & $\boldsymbol{\sigma}_{\mathbf{c}}(\mathbf{k P a})$ & $\mathbf{O C R}$ \\
\hline 1 & $5-5.5$ & $\mathrm{Y}$ & $\mathrm{CI}$ & 45 & 1.19 & 17.33 & 100 & 0.338 & 0.023 & 57 & 105 & 1.8 \\
\hline
\end{tabular}

\section{Derin Kazı Analizi}

Söz konusu işyeri projesinde kazı derinliği 9.50 m olarak öngörülmüştür. Çalışma alanının doğu cephesinde mevcut 5 katlı betonarme yapı bulunmaktadır. Yapıdan zemine aktarılan temel gerilmeleri statik durumda $90 \mathrm{kPa}$ dolaylarındadır. Parselde yapılan sondaj çalışmalarında YASS' nin -3.0 m kotunda olduğu bildirilmiştir. Alanda daha önce inşa edilmiş ve güncel durumda yıkılarak temeli kaldırılmış yapının inşası aşamasından kalan parselin alan olarak \%60' lık kısmında çepeçevre $11 \mathrm{~m}$ derinliğinde kazıklı perde oluşturulmuş olduğu anlaşılmıştır. Yeni proje dolayısıyla parselin tamamını içeren bir destek sistemi ihtiyacı bulunmaktadır. Bu durumda yeni inşa edilecek olan destek sistemi hali hazırda mecut bulunan kısımlarda bu eski perdenin önünde oluşturulmuştur. Destek sisteminin planı ise Şekil 3' te verilmektedir.

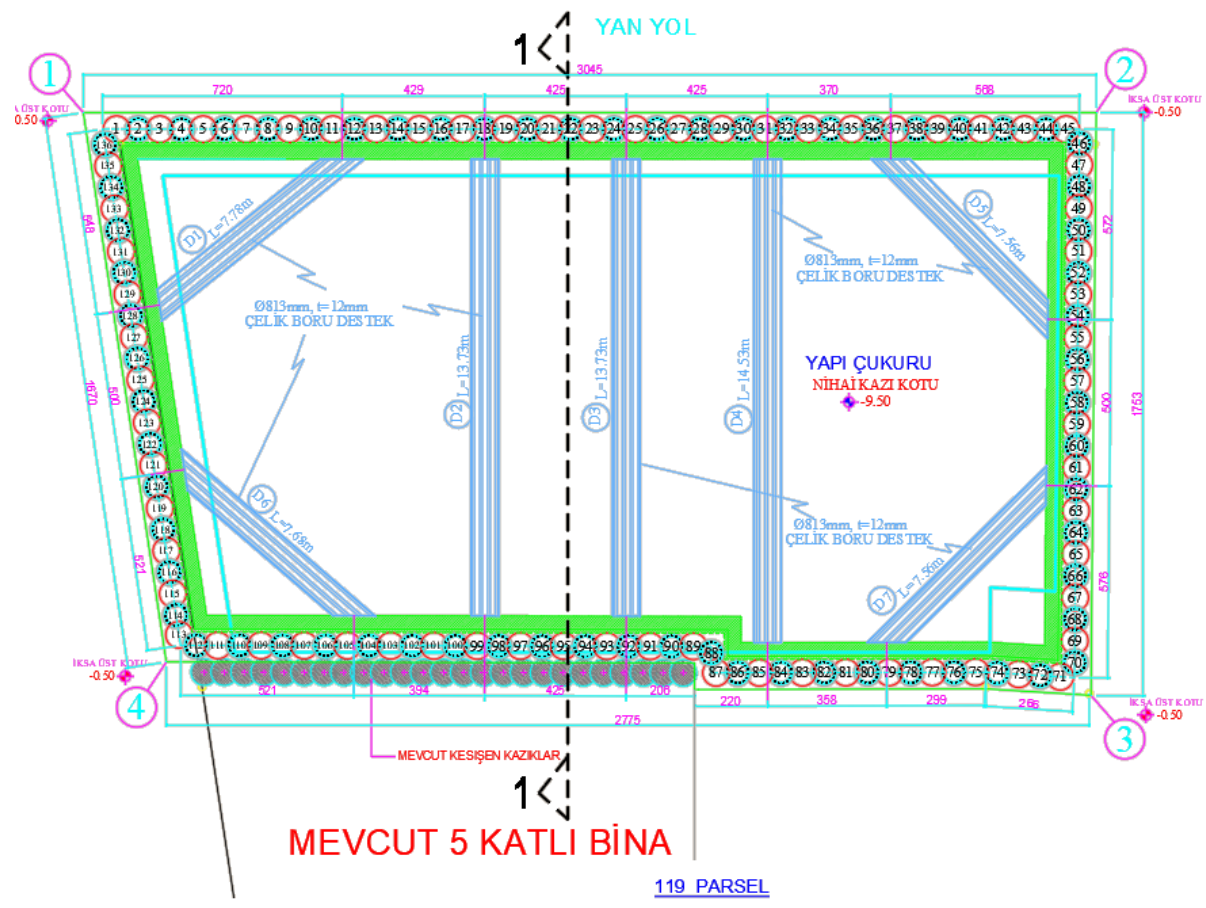

Şekil 3. Kesişen kazıklı perde destek sistemi planı

$\mathrm{Bu}$ veriler ışığında yukarıda bahsedilen zemin parametreleri kullanılarak derin kazı analizi yapılmıştır. Analiz sonucuna göre $17.3 \mathrm{~m}$ boyunda 80/65 cm çapında kesişen kazıklı perde ve $3.50 \mathrm{~m}$ kotunda yer alan çelik destek (strut/prop) ihtiva eden çözümün kısa vadede güvenliği sağlayacağı anlaşılmıştır. Şekil 3' te verilen kesit özeti doğrultusunda güvenlik katsayısı 1.41 olarak hesaplanmıştır. Bu durumda perdeye gelecek maksimum eğilme momenti $814 \mathrm{kNm} / \mathrm{m}$, maksimum kesme gerilmesi $344 \mathrm{kN} / \mathrm{m}$ olacaktır. 


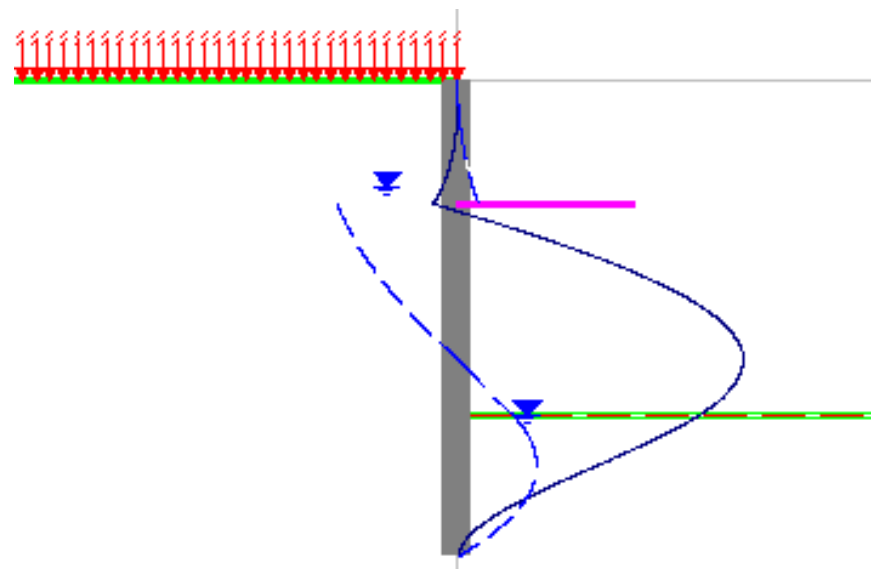

Şekil 4. Kesişen kazıklı perde destek sistemi kesiti

\section{Deformasyon Okumaları}

Temel kazısı öncesi kesişen kazıklı perdenin inşasından sonra -4.0 m kotuna kadar yer alan eski yapı betonarme temel kırılarak çıkartılmış ancak söz konusu parsel sınırının doğu kenarına sıfır konumda yer alan 5 katlı komşu yapıda yapılan ölçümlerde düşey ve yatay deformasyonların belirdiği anlaşılmıştır. Şekil 5' te zamana bağlı olarak komşu binada gerçekleşen deformasyon okumaları grafiği verilmiştir. Şekil 6' da ise inklinometre sonuçları görülebilmektedir.

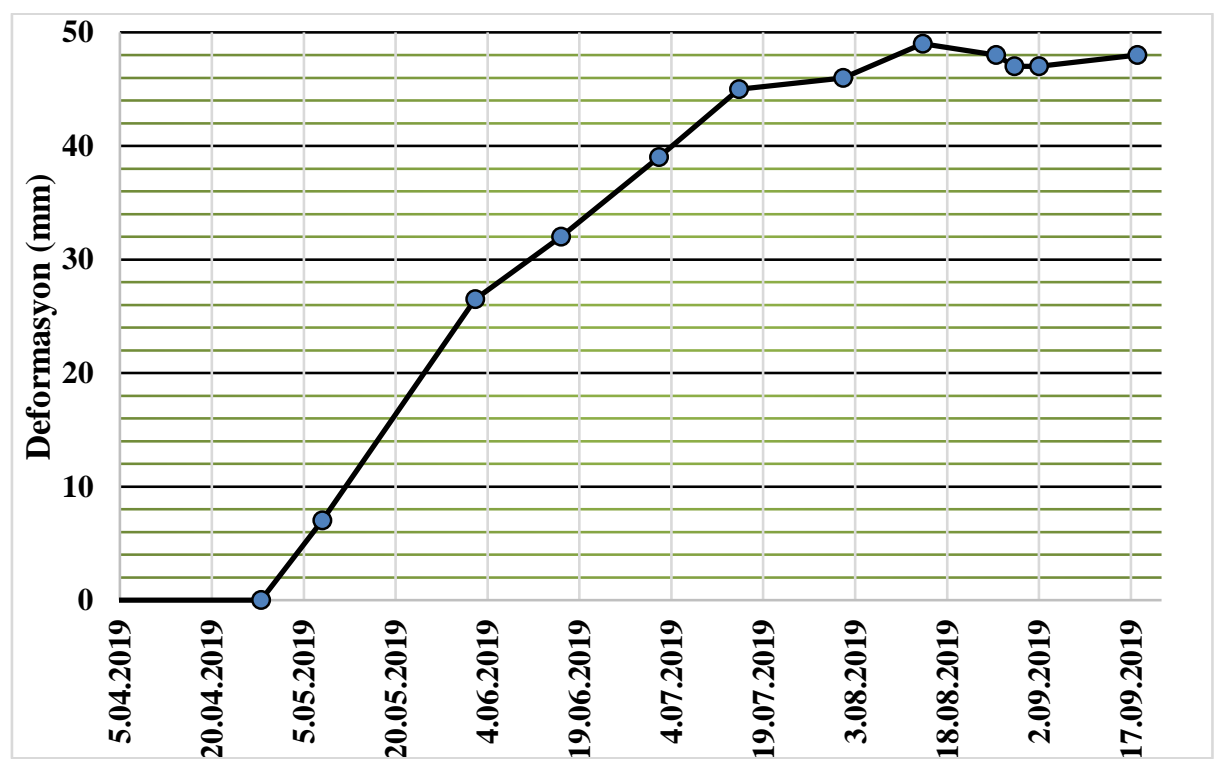

Şekil 5. Deformasyon okumaları 


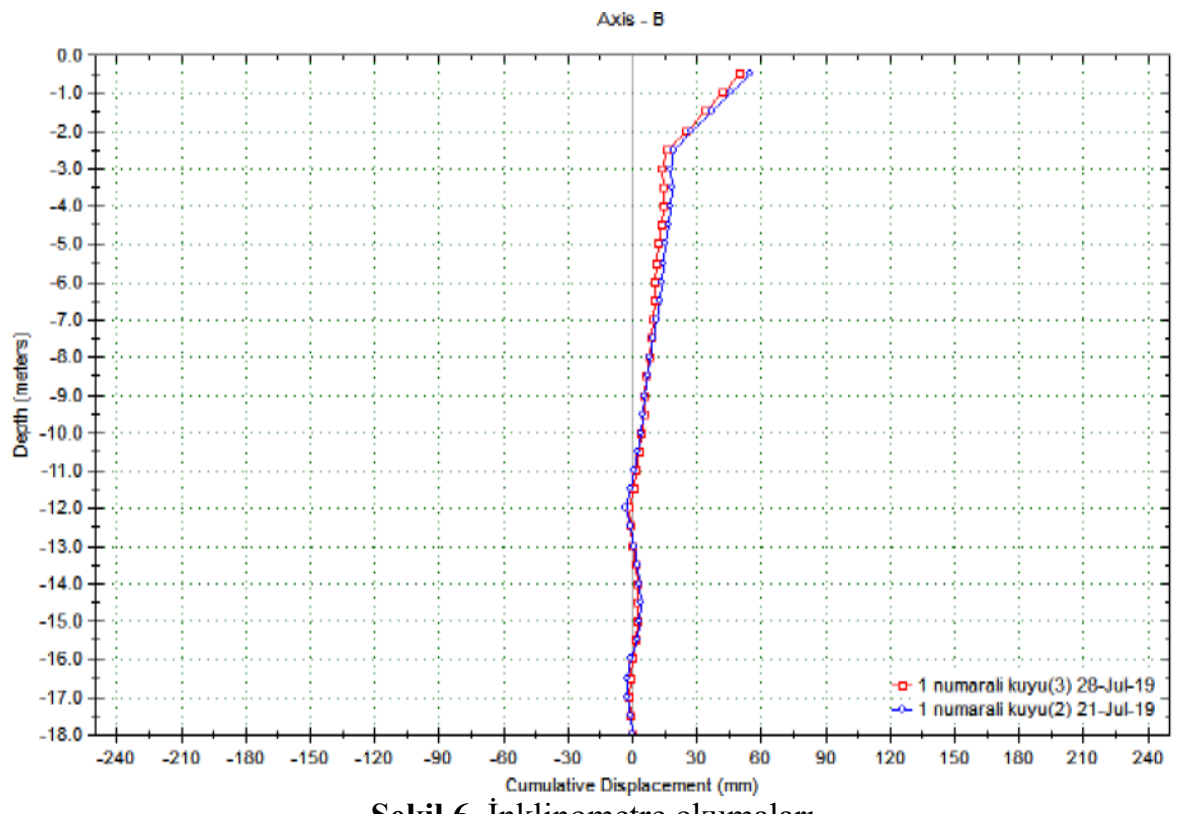

Şekil 6. İnklinometre okumaları

Şekil 5 ve Şekil 6'da görülebilen deformasyonların kazıklı perdenin inşası ve $4 \mathrm{~m}$ derinlikteki eski temelin çıkarılıp yerine kontrolsüz dolgu aşamasından sonra gerçekleştiği bilinmektedir. Bu duruma özellikle kazıkların imali sırasında foraj aşamasında yeraltı suyunda ani drenajın gerçekleşmesinin ve bunun sonrasında bitişik nizamda bulunan mevcut 5 katlı yapının altında yer alan özellikle killi tabakaların konsolide olmasının neden olduğu tahmin edilmiştir. Yani okumalarda gelişen deformasyonlara konsolidasyon oturmalarının neden olduğu düşünülmüştür. $\mathrm{Bu}$ aşamada konsolidasyon oturmalarının tamamlanması için inşa çalışmalarına ara verilmesi önerilmiş olup işverence buna uyulmuştur. Sonrasında günde iki kez yapılan deformasyon ölçümlerinde okumalar stabil hale geldikten sonra kazı çalışmalarına kontrollü olarak devam edilmiştir.

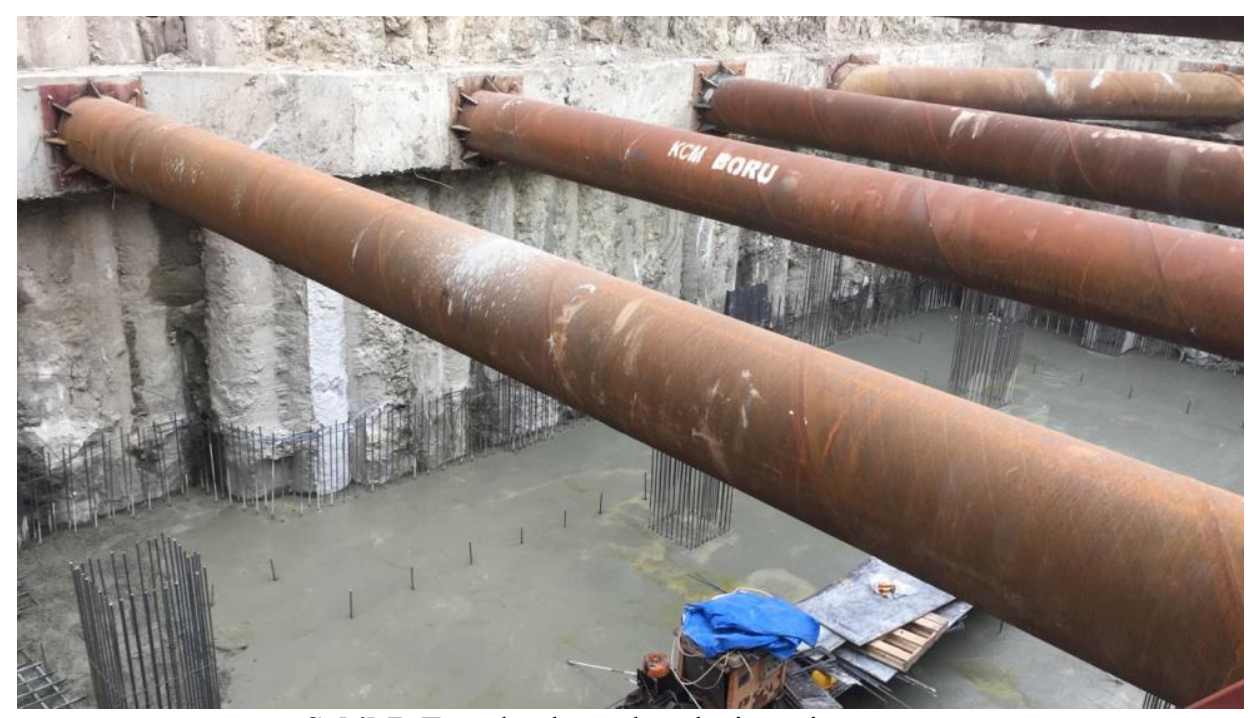

Şekil 7. Temel çukuru destek sistemi görünüşü 
Deformasyon okumaları kararlı hale geldikten sonra temel çukuru parselin arkasından itibaren 5 m derinliğe kadar kazılmaya başlanmış ve arka çapraz destekler yerleştirilmiştir. Kazı çalışması, çalışma alanının darlığından kaynaklanan kazı zorluğu nedeniyle kazı ve desteklerin sırayla yerleştirilmesi aşamaları izlenerek tamamlanmıştır. Bu sırada günde iki kez olmak üzere deformasyon okumaları takip edilmiş, projedeki desteklerin yanı sıra kazı aşamasında zemin yüzeyi kotunda başlık kirişleri seviyesinde iki adet geçici destek uygulaması da ayrıca ilave edilmiştir. Şekil 7'de kazı aşamasının tamamlanıp temel betonunun imali sonrası görünüm yer almaktadir.

\section{Sonuçlar ve Öneriler}

Sakarya ilinde yer alan çalışma alanında inşası planlanan yapının derin kazısı ile ilgili olarak destek sistemi boyutlandırması yapılmıştır. Çalışma alanının doğu cephe sınırında 5 katlı betonarme bina mevcut durumdadır. $9.50 \mathrm{~m}$ derinliğinde planlanan temel çukuru kazısı öncesi kesişen kazıklı perde ve tek sıra destek uygulaması önerilmiştir.

İmalat aşamasında destek sisteminde ve komşu yapılarda düşey ve yatay deformasyon okumaları alınmıştır. Kazıklı perdenin imalatını takiben gerçekleştirilen $4 \mathrm{~m}$ derinliğindeki kazı ve doldurma aşaması sonrası özellikle doğu cephesindeki deformasyon okumaları dikkat çekmiştir. $\mathrm{Bu}$ durumun özellikle kazıkların imali sırasında yeraltı suyunda ani drenajın gerçekleşmesi, bunun sonrasında ise bitişik nizamda bulunan mevcut 5 katlı yapının altında yer alan özellikle killi tabakaların konsolide olmasından dolayı kaynaklandığı tahmin edilmişstir.

Kazı çalışmasına deformasyon okumalarının kararlı hale gelmesine dek ara verilmiş, kazı ve destek sisteminin imalatı aşamalar halinde kontrollü olarak sürdürülmüşstür. Tüm bu çalışmalar süresince arazi ölçümleri hassasiyetle taklip edilmiştir. Kazı çalışması güncel durum itibarıyla tamamlanmış olup göreceli olarak küçük bir parselde gerçekleştirilen uygulamalar sürecinde derin kazı destek sisteminde destek (strut) uygulamasının pratikte kazı aşamasında uygulama zorluğu yarattığı gözlemlenmiştir.

\section{Kaynaklar}

[1] Sarıaslan MM, Yurdakul ME, Osman ÇR, Keçer M, Basa F, Şentürk K. Sakarya ilinin çevre jeolojisi ve doğal kaynakları. MTA Raporu, No. 10195, 1998.

[2] Komazawa M, Morikawa H, Nakamura K, Akamatsu J, Nishimur K, Sawada S, Erken A, Önalp A. Bedrock structure in Adapazarı, Turkey: a possible cause of severe damage by the 1999 Kocaeli earthquake. Soil Dyn Earthq Eng 2002; 22:829-36.

[3] Bol E, Adapazarı zeminlerinin geoteknik özellikleri, Doktora Tezi, SAÜ, FBE 2003.

[4] TSE. TS1900-I İnşaat mühendisliğinde zemin laboratuvar deneyleri - Bölüm I: fiziksel özelliklerin tayini. Ankara; 2006.

[5] TSE. TS1900-II İnşaat mühendisliğinde zemin laboratuvar deneyleri - Bölüm II: mekanik özelliklerin tayini. Ankara; 2006. 